\title{
Caudal Regression Syndrome: A Case Report
}

\author{
Sadia Afrin Mony ${ }^{1}$ \\ Tanuka Barua' \\ Md Badruddoza'
}

'Department of Pediatrics

Chattagram Maa-Shishu-O-General Hospital

Chittagong, Bangladesh.
*Correspondence to:

\section{Dr. Sadia Afrin Mony}

Medical Officer

Department of Pediatrics

Chattagram Maa-Shishu-O-General Hospital

Chittagong, Bangladesh.

E-mail: dr.sadia.af@gmail.com

Mobile : +88 01717-711988

www.banglajol.info/index.php/CMOSHMCJ

\begin{abstract}
Caudal Regression Syndrome (CRS) is a spectrum of congenital malformations, which consist of anomalies of the rectum, the urinary and genital systems, the lumbosacral spine, and the lower limbs. Though exact cause that leads to caudal regression syndrome is still unknown but it is believed that genetic influence as well as maternal pathologic factor related to carbohydrate metabolism plays an important role. The severity of morphologic disorder depends on residual spinal cord function. Infant may present with mild to severe neurological involvement with or without visceral anomaly. Here, we report a case of caudal regression syndrome in an 18 months old girl and presented with hypoplastic lower limb and bladder incontinence.
\end{abstract}

Key words: Caudal regression syndrome; Sacral agenesis; Lumbosacral spine.

\section{INTRODUCTION}

Caudal regression syndrome is a rare congenital malformation of the lower spinal segments associated with aplasia or hypoplasia of sacrum \& lumber spine ${ }^{1}$. The concept of this syndrome was outlined by Duhamel ${ }^{2}$. Incidence is $1: 7,500$ to $1: 60,000$ birth $^{3,4} \&$ may extend from lower thoracic vertebrae to coccyx level with affecting lower extremity ${ }^{4,5}$. Male $\&$ female ratio is $2.7: 1^{3,6}$. There is a spectrum of anomalies of the caudal end of the trunk, malformations vary from isolated partial agenesis of the sacrococcygeal spine to more severe deformities. These developmental anomalies can result in deformities of the pelvis, anomalies of lower extremities \& motor \& neurological deficits of varying degrees of severity ${ }^{1}$. This syndrome usually accompanied by congenital anomalies involving multiple systems such as renal ectopia, unilateral or bilateral renal agenesis, fused ureters, neurogenic bladder, enuresis or vesico-ureteric reflux. It may also include anomalies like imperforated anus, anorectal atresia, tethered cord, diastematomyelia, lipomyelomeningocoele, congenital narrow spinal tract, scoliosis, hip dislocation and contracture, narrow pelvis, syringomyelia, club foot, frog leg ${ }^{5}$.

\section{CASE REPORT}

An 18 month old girl presented with the complaints of increased frequency of micturition since birth. She also has difficulty in defaecation described by her mother with excessive strain, sometimes with protrusion of part of the anus. She had congenitally inverted left foot which was treated in her early infancy. She was the 3rd child of a non-diabetic mother \& consanguinous marriage was not the case for her parents. There was no history of antenatal infection, radiation exposure or maternal hypertension. But she used to take homeopathic drug in early pregnancy \& did not take any folinic acid before 7th month of pregnancy. She underwent LUCS at term for fetal distress. It was ascertained that there were no similar congenital deformities in other family members including a healthy sib of patient. But her another sib who died at 18 month of age, had both motor \& cognition delay \& used to bite $\&$ injure his own body parts. 
On physical examination, patient was having normal craniofacial development, no other limb deformity except varus position of knees. Important finding was narrow hip, underdeveloped gluteal muscles, short intergluteal cleft, vertebral protruberence \& indentation on skin beside it over lower back. It was associated with reduced muscle mass in both legs. In locomotor system examination, lower extremities of patient were hypoplastic, but muscle tone, power \& deep reflexes are normal. No abnormalities were detected in upper extremities, no abdominal muscle weakness or genital abnormality. Developmentally she cannot walk without support, but there is no delay in other domains \& she has normal intelligence for her age.

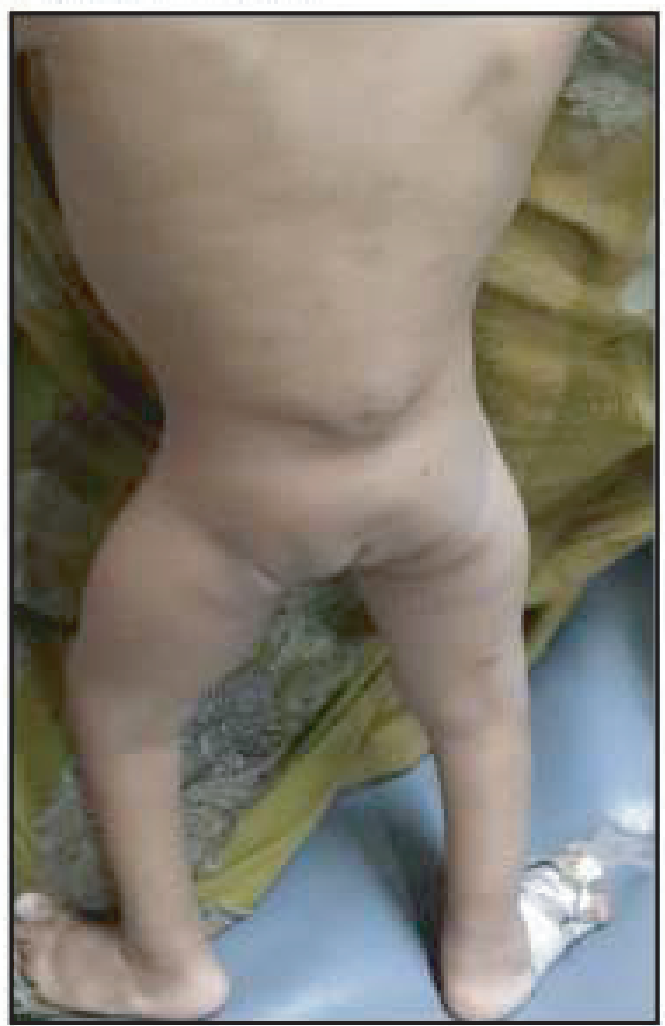

Preliminary radiograph of sacral region was taken. The findings showed deficient sacral elements indicative of sacral agenesis. MRI being the investigation of choice was performed. MRI revealed absent sacrum with fusion of both iliac bones. Also there was abrupt end of spinal cord noted higher than the usual level of lower border of LI body. In this case the cord showed abrupt club shaped end with termination at level of D12. The nerve roots of cauda equina appear normal. Certain other important findings were noted like absence of any intraspinal space occupying lesion, normal paraspinal soft tissues and sacroiliac joints. No evidence of pelvic structural anomalies were seen. Both kidneys appeared to be normal. Based on MRI, we concluded with the diagnosis of caudal regression syndrome type 2 as per classification of lumbosacral agenesis by Pang et al?
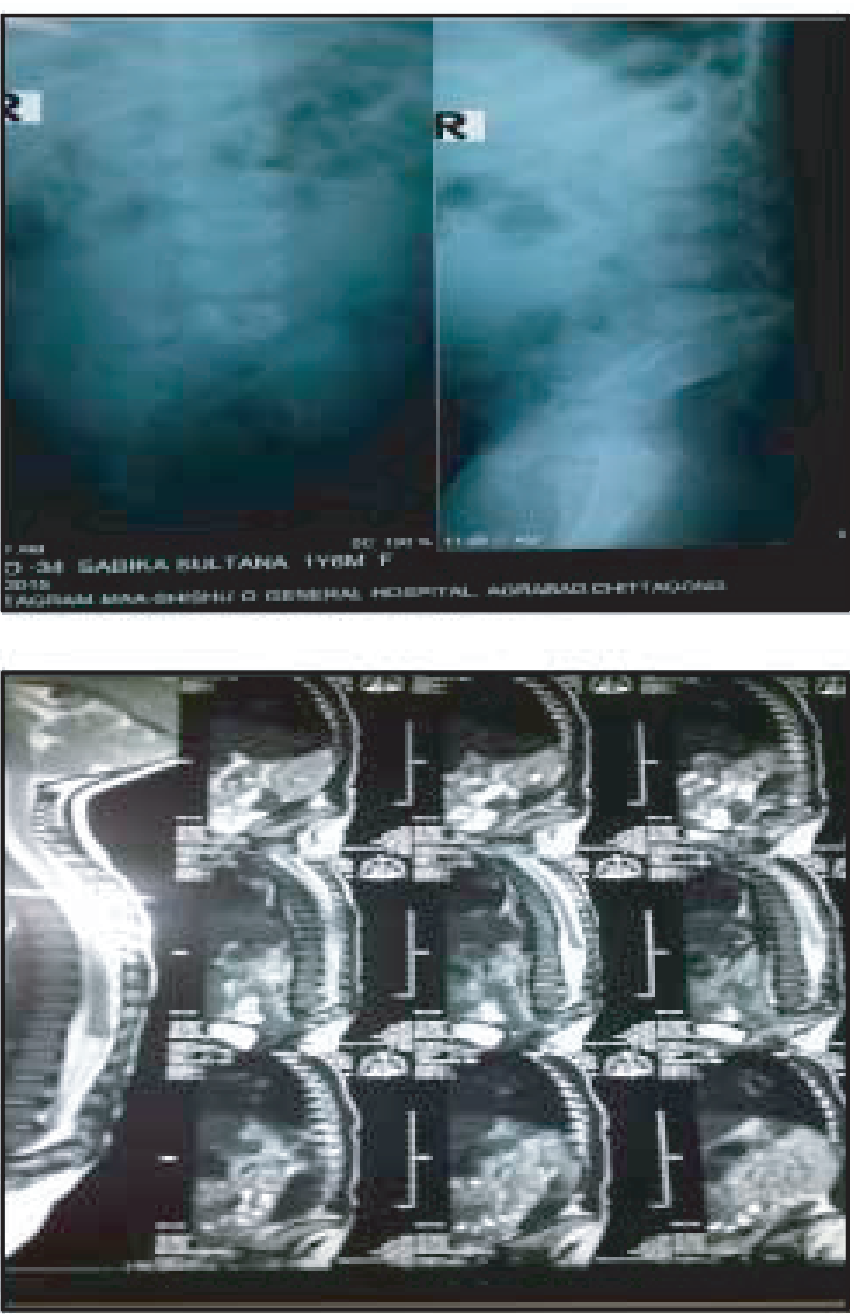

DISCUSSION

There are several explanations in the mechanism of pathogenesis of CRS. These include disturbance of the primary or secondary neurulation ${ }^{7,8}$. Development central nervous system involves primary and secondary neurulation that occur on the dorsal aspect of the embryo ${ }^{9}$. Primary neurulation involve the formation of brain and spinal cord. Secondary neurulation starts after primary neurulation ${ }^{10}$. During this period, the caudal end of the neural tube and the caudal end of notochord blend into caudal cell mass. The caudal cell mass extends into the tail fold, adjacent to the distal end of the developing hindgut and the mesonephros. Thus the juxtaposition of developing hindgut, genitourinary, notochordal, and neural structures within the tail fold accounts for the common association of distal vertebral, neural, anorectal, renal, and genital anomalies, usually observed in $\mathrm{CRS}^{10}$.

Though Duhamel considered sirenomelia (Fused bones of lower limbs ) as a type of caudal regression syndrome but some authors disagreed with that. Twickler et al and Jones considered sirenomelia as a separate entities and asserted that these are unrelated pathogenetically ${ }^{2,11,12}$. Rudd and Klimek described a pathogenetic link exists between these ${ }^{13}$. 
CRS is about 200 times more prevalent in patients with a maternal history of Insulin-Dependent Diabetes Mellitus (IDDM). ${ }^{14}$ The incidence of CRS is $16 \%$ to $22 \%$ in infants of diabetic mother against $0.2 \%$ to $1 \%$ in infants of nondiabetic mother ${ }^{11,14}$. These observation support the role of environmental factors such as hyperglycemia, insulin, antibody to insulin, abnormality of carbohydrate metabolism or hormone balances as potential teratogens ${ }^{15,16}$. The etiology cannot be explained by the environmental factors only. In several cases, a sacral defect has been inherited and there has no association with maternal diabetes. In few children, caudal regression syndrome may be associated with mutations of the VANGL1 gene located on the short arm (p) of chromosome 1 (1p13). This mutation is inherited as an autosomal dominant trait $^{17}$. Chromosomal studies revealed normal in some studies ${ }^{18}$. In some cases, caudal regression syndrome reported in siblings also $^{19}$. Zew and Stone observed one of a set of identical twins of diabetic mother living in the same environment did not develop caudal regression syndrome suggesting role of genetic or other influence besides environmental factors. ${ }^{15}$ The mother of the patient, we report, was nondiabetic also and one of her sib died at 18 months of age with motor and cognition delay but cause of motor delay was not identified as was attended by physician just after death. So several different environmental factors in addition, different genetic factors may play a causative role in different people (Genetic heterogeneity).Welch and Aterman postulated that sacral agenesis resulted when an embryo with a genetic predisposition to the condition was exposed to some factor in the diabetic uterus ${ }^{20}$. There may be an association between caudal regression syndrome and VACTERL defect (Vertebral, anal, cardiac, tracheo-esophageal fistula, renal, and limb) which supports the theory that these entities may be different manifestations of a single pathogenic process ${ }^{21,22}$.

Infants with caudal regression syndrome may only have isolated abnormal development of the sacrum or the sacrum may be absent altogether ${ }^{17,23}$. Sacral agenesis is often associated with narrowing of the hips, hypoplastic gluteal muscles, an indentation on the skin of the lower back ${ }^{17,23}$. Abnormalities of the lumber vertebrae may also occur ${ }^{17}$. We had the patient had underdeveloped lower limb with flattened buttock, hypoplastic thigh and legs, short intergluteal cleft and vertebral protuberance with sacral agenesis revealed on lumbosacral $\mathrm{X}$ ray. Like some caudal regression syndrome patients the child had urinary incontinence since birth, may be due to abrupt end of lower portion of spinal cord ${ }^{15,17,23}$. Abnormalities of the spinal cord and lower limbs may causes disruption of the lower portion of the spinal cord resulting in variety of neurological abnormalities including defective bladder and bowel control, increased urinary frequency, and failure of the bladder to empty completely (Neurogenic bladder) ${ }^{15,17,23}$.
Damage to the nerves causes abnormalities of the lower limbs such as flexion contractures of the knee and hip, fixed flexion or extension, deformity of tarsal, metatarsal etc. ${ }^{15,17,23}$. Affected infants may also have clubfeet or webbed skin on the back of the knees ${ }^{22,23,24}$. The severity of lower limb abnormalities can vary. Some individuals will walk unassisted; others may need an assistance device ${ }^{17}$. Our patient was treated for clubfoot for 3 months prior to admission but locomotor system and neurological examination was normal except presence of hypoplastic lower limbs and bladder incontinence.

Caudal regression syndrome may exist with no obvious outward signs, thus diagnosis is often delayed until failed attempts at toilet training bring the child to the attention of a physician $^{25,26}$. The neurologic manifestations including motor and sensory deficits usually correspond to the level of vertebral agenesis, although in some patients, the sensory functions persist below this level ${ }^{25}$. There may be delay in achieving developmental milestone or no delay at all ${ }^{22,24}$. Intelligence remain normal and infant can lead normal life in absence of major visceral anomaly and unaffected or minimally affected neurological system ${ }^{17}$. When these children are evaluated in the newborn or early infancy period, the majority have a perfectly normal neurologic examination ${ }^{24}$. Similarly, our patient presented with normal neurological findings with no developmental delay. Sometimes urological examinations including a urodynamic study might be the only clue of an underlying neurologic injury. Abnormal lower urinary tract function were found in about one-third of babies younger than 18 months old on urodynamic testing. ${ }^{27}$. Y Moitoki et al report a case of neuropathic bladder caused by CRS without any neurogenic symptoms ${ }^{24}$.

Kidney abnormalities that occur in caudal regression syndrome are renal agenesis, renal ectopia, malrotated kidney, fused ureters resulting in urinary obstruction, neurogenic bladder, vesicoureteral reflux etc ${ }^{17,22,28}$. Our patient had no any obvious anomalies except anal atresia, renal function test revealed normal and MRI of lumbosacral spine was abrupt cessation of spinal cord at the level of T12 which is higher than normal level. MZ Seidahmed et al also found similar findings ${ }^{28}$.

We report a case of caudal regression syndrome with normal renal and neurologic function except urine incontinence and with lack of any gross anomalies or developmental delay in any domain. Survival is expected and screening of UTI, renal function and urologic test should be done regularly due to presence of urinary incontinence.

\section{DISCLOSURE}

All the authors declared no competing interest. 


\section{REFERENCES}

1. Solomon BD. VACTERL / VATER Association. OJRD. 2011;6:56

2. Duhamel B. From the Mermaid to Anal Imperforation: the Syndrome of Caudal Regression. Arch Dis Child. 1961;36:152-155.

3. Knight B. Caudal Regression Syndrome: A Case Report. AANA Journal. 2011;79(4):281-282.

4. Bicakci I, Turan S, Turgut B et al. A Case of Caudal Regression Syndrome: Walking or Sitting ? Pan African Medical Journal. 2014;18:92.

5. Claudia MR, Erik M, Juan DC, Andres G, Andreina MA. A Rare Case of Caudal Regression Syndrome Linked to Tethered Cord and Dermal Cysts. J Spinal Surg. 2014;1(3):132-134

6. Fenn DJ, Balachandar V, Sareswathi K, Priyadharshini SM. Non-diabetic Maternal Factor with Caudal Regression Syndrome : A Novel Case Report. Int J Pharm Bio Sci. 2015;6(1):222-228.

7. Pang D. Sacral Agenesis and Caudal Spinal Cord Malformations. Neurosurgery. 1993;32:755-778.

8. Nievelstein RA, Valk J, Smit LM et al. MRI of the Caudal Regression Syndrome: Embryologic implications. Am J Neuroradiol. 1994;15:1021-1029.

9. Volpe J. Neurology of the Newborn. Philadelphia: W.B. Saunders. 1995; 4-5.

10. Naidich T, Zimmerman R, McLone DG et al. Congenital Anomalies of the Spine and Spinal Cord: Embryology and Malformations. In: Atlas S, editor. Magnetic Resonance Imaging of the Brain and Spine. Philadelphia: Lippincott-Raven. 1996; 1265-1337.

11. Twickler D, Budorick N, Pretorius D et al. Caudal Regression Versus Sirenomelia: Sonographic Clues. J Ultrasound Med. 1993;12:323-330.

12. Jones KL. Smith's Recognizable Patterns of Human Malformation. Philadelphia, WB Saunders Co. 1997.

13. Rudd NL, Klimek ML. Familial Caudal Dysgenesis: Evidence for a Major Dominant Gene. Clin Gene. 1990;38:170-175.

14. Subtil D, Cosson M, Houfflin V et al. Early Detection of Caudal Regression Syndrome: Specific Interest and Findings in Three Cases. Eur J Obstet Gynecol Reprod Biol. 1998;80:109-112.

15. Zaw W and Stone DG. Caudal Regression Syndrome in Twin Pregnancy with Type II Diabetes. J Perinatol. 2002;22:171-174.

16. Mills JL. Malformations in Infants of Diabetic Mothers. Teratology. 1982;25:385-394.

17. Chervenak F. Caudal Regression Syndrome. http://rarediseases.org/rare-diseases/caudal-regression-syndrome/

18. Perrot LJ, Williamson S, Jimenez JF. The Caudal Regression Syndrome in Infants of Diabetic Mothers. Ann Clin Lab Sci. 1987;17:211-220.

19. Finer NN, Bowen P, Dunbar LG: Caudal Regression Anomaly in Siblings. Clin Genet. 1978;13:353-358.

20. Welch JP, Aterman K: The Syndrome of Caudal Dysplasia: A Review, including Etiologic Considerations and Evidence of Heterogeneity. Pediat Path. 1984;2:313-327.

21. Moosa S, Lambie LA, Krause A. Sirenomelia: Four Further Cases with Discussion of Associated Upper Limb Defects. Clin Dysmorphol. 2012;21:124-130.

22. Seidahmed M, Omer B, Basit A, Khalid A. Hussein A et al. Sirenomelia and Severe Caudal Regression Syndrome. Saudi Med J. 2014;35(Suppl 1):S36-S43.

23. Kaissi A, Klaushofer K and Franz Grillhttp://www.casesjournal.com/content/1/1/407/ - ins2. Caudal Regression Syndrome and Popliteal Webbing in Connection with Maternal Diabetes Mellitus: A Case Report and Literature Review. http://www.casesjournal.com/content/1/1/407 (Published on December 2008)

24. Moritoki Y, Kojima Y, Kamisawa H et al. Neuropathic Bladder Caused by Caudal Regression Syndrome without Any Other Neurogenic Symptoms. Hindawi Publishing Corporation. http://dx.doi.org/10.1155/2012/982418 (Accepted on 30 April 2012)

25. Anderson FM. Occult Spinal Dysraphism: A Series of 73 Cases. Pediatrics. 1975;55(6):826-835

26. Bauer SB. Neurogenic Voiding Dysfunction and Non-surgical Management. In: The Kelalis-King-Belman Textbook of Clinical Pediatric Urology. S. G. Docimo, D. A. Canning, and A. E. Khoury Eds. Informa Healthcare, London, UK. 2007;5:781-818.

27. Farhat W, Bagli DJ, Capolicchio G et al. The Dysfunctional Voiding Scoring System: Quantitative Standardization of Dysfunctional Voiding Symptoms in Children. J Urol. 2000;164(3):1011-1015.

28. Torre M, Guida E, Buffa P et al. Risk Factors for Renal Function Impairment in a Series of 502 Patients Born with Spinal Dysraphisms. J Pediatr Urol. 2011;7(1):39-43. 